\title{
The Creative Class: do Jobs follow People or do People follow Jobs?
}

\author{
Stein Østbye ${ }^{a *}$, Mikko Moilanen ${ }^{b}$, Hannu Tervo ${ }^{c}$ and Olle Westerlund ${ }^{d}$ \\ ${ }^{a}$ School of Business and Economics, UiT The Arctic University of Norway, P.O. Box 6050 \\ Langnes, NO-9037 Troms $\emptyset$, Norway. Email: stein.ostbye@uit.no \\ ${ }^{b}$ School of Business and Economics, UiT The Arctic University of Norway, P.O. Box 6050 \\ Langnes, NO-9037 Tromsø, Norway. Email: mikko.moilanen@uit.no \\ ${ }^{c}$ Jyväskylä University School of Business and Economics, P.O. Box 35, FI-40014 University \\ of Jyväskylä, Finland. Email: hannu.t.tervo@jyu.fi \\ ${ }^{d}$ Umeå School of Business and Economics, Umeå University, SE-90187 Sweden. Email: \\ olle.westerlund@econ.umu.se
}

\begin{abstract}
Regional adjustment models are applied to explore causal interaction between two types of people distinguished by educational attainment, and two types of jobs, creative class jobs and other jobs. Data used are for labour market regions in Finland, Norway and Sweden from the 2000s. Creative class jobs follow people with high educational attainment (one way causation), but creative class jobs also follow other jobs and vice versa (circular causation). The results suggest that stimulating creative class job growth could be accomplished through attracting people with higher education, but also through attracting other jobs with the added benefit that the initial stimulus would be reinforced through circular and cumulative causation between job creation in the two sectors.
\end{abstract}

\section{KEYWORDS}

creative class, regional adjustment, sectoral dynamics, Northern Europe

JEL CLASSIFICATION

C33, O18, R11

\section{INTRODUCTION}

Is regional growth induced by labour demand or labour supply? A large body of literature, beginning with MUTH (1971) and expanding rapidly after CARLINO and MILLS (1987), has attempted to answer this question that is often more colloquially phrased in the words of STEINNES (1977): do 'Jobs follow People' or do 'People follow Jobs'?

\footnotetext{
*Corresponding author.
} 
The primary question concerns bidirectional causality or circular causation, and the answer has important implications for policy guidance. When people follow jobs, growth is induced by labour demand and policies should target jobs; when jobs follow people, growth is induced by labour supply and policies should target people. When causality runs both ways, the relative magnitudes of the feedback become important in the design of efficient policy, and the real issue is which effect is stronger, not the direction of causality (MASSEY, 1990).

The numerous empirical studies conducted since CARLINO and MILLS (1987) have produced mixed evidence. A comprehensive review of this literature is not possible within the space constraints, but the interested reader is referred to two surveys that are available. MULLIGAN et al. (1999) provide a good survey and robustness analysis of some of the early studies employing the Carlino-Mills framework, and HOOGSTRA et al. (2005) survey additional studies and study robustness in a statistical meta analysis framework.

The explanation for the mixed results could in part be due to compositional effects from aggregation over different mechanisms that might be resolved by examining more specific subgroups and their interaction within a multisectoral framework. Aggregate data may conceal the existence of different patterns among different subgroups (jobs or people). CARLINO and MILLS (1987) already recognized this and not only studied aggregates but also whether manufacturing jobs followed people and vice versa. However, intersectoral dynamics were ignored and have remained neglected in the literature, with the notable exception of DE GRAAFF et al. (2012), presenting a multisectoral econometric model of population-employment dynamics of the Carlino-Mills type that are estimated using data for the Netherlands.

One subgroup of particular interest is the 'creative class', a subgroup that has received considerable attention over the last decade, not least due to the widely read book by FLORIDA (2002b). Surprisingly, the creative class literature appears to have ignored potential circular causation by assuming away the People follow Jobs hypothesis (STORPER and SCOTT, 2009). This could bias results and lead to unwarranted policy recommendations in favour of labour supply policies rather than labour demand policies, for example by stimulating amenities and ignoring business climate. ${ }^{1}$

The framework used here allows for circular causation between jobs and people, as in all Carlino-Mills studies, but for the first time the framework is applied to the study of the creative class. The study argues that, empirically, the creative class is an attribute more related to jobs than to people. 'Human capital', which is often offered as an alternative to creative class as an explanatory variable, is thus a complement rather than a substitute, as it is an attribute related more to people than to jobs. ${ }^{2}$ Therefore, the analysis includes both concepts allowing the investigation of the bidirectional relationship between creative class jobs and highly educated people.

Disaggregating concepts allows for an interaction between the parts. New questions that might be answered are for example whether non-creative class jobs follow creative class jobs and whether people who have not obtained higher education follow those who have (or vice versa). The framework enables a richer description and gives a deeper understanding of the underlying mechanisms, mechanisms that may, for example, be related to demand linkages emphasized in the New Economic Geography literature. It also provides a basis for analysing intersectoral dynamics within the Carlino-Mills framework. Recently, DE GRAAFF et al. (2012) began exploring this avenue based on standard sectoral employment classifications, but they continue to consider a homogenous population, whereas this article offers a non-standard sectoral classification by introducing the creative class category within a multisectoral framework and allows 
for population heterogeneity with respect to educational attainment.

The data are for regional labour market areas (corresponding to the former European NUTS 4 level) from three Nordic countries: Norway, Sweden and Finland (for a total population of 20 million) totalling 250 regions. This is a relatively large sample of spatial units that are functional regions and not only based on administrative borders or other convenience criteria. The authors are aware of two other studies in the Carlino-Mills tradition based on Nordic data, but none of these use a multisectoral framework and data for more than one country (SÖRENSSON, 2012 and TERVO, 2016).

In summary, this paper contributes to the literature both conceptually and empirically. Conceptually, human capital and creative class are integrated within a unified multisectoral regional adjustment model that allows for bidirectionality in the growth process within and between sectors. Empirically, the paper provides new evidence on regional growth by estimating a model based on a unique dataset covering functional regions for Sweden, Norway and Finland. Notably, the results emphasize that simple maxims such as Jobs follow People or People follow Jobs based on aggregates may offer poor guidance for policy because the complex causal interaction beneath the surface suggests that one policy does not fit every sector.

The remainder of this article is organized into five main sections. Conceptual issues are briefly discussed in the next section, followed by an introduction to the underlying theoretical and empirical model. Then data and results are presented before the paper finishes with a concluding discussion. The reader may also find the Appendix useful, as it provides further details on the model, data and results (available as supplemental electronic material).

\section{CONCEPTUAL ISSUES}

In many empirical studies, the creative class has simply been defined as a set of categories from the International Standard Classification of Occupations (ISCO). An example is a study of seven European countries (including Sweden, Norway and Finland) reported in BOSCHMA and FRITSCH (2009). This study will not challenge the use of ISCO codes to transform the creative class into an operational concept. The point to be made, however, is that in operationalizing the concept, one should be careful not to treat the creative class as a group of people. Consistent with the principles underlying the ISCO classification, one should rather discuss creative class jobs. ${ }^{3}$

By implication, it is not sensible to discuss creative class and human capital as comparable concepts where one may serve as a substitute for the other. Human capital, also when defined in operational terms as educational attainment, is unmistakably a personal attribute. It is sticky in the sense that one cannot rid oneself of one's years of schooling but can only add to them through investments in additional education throughout one's life. It is misleading to present creative class as an alternative to human capital when, in fact, they are complementary attributes residing in two different hosts, the job and the human being.

This argument fits well into the Carlino-Mills framework and makes it possible to address the prior neglect of potential labour-demand-induced growth in the creative class literature noted by STORPER and SCOTT (2009). From a firm location perspective, access to a well-qualified local labour pool is important. To the extent that the labour qualified for creative class jobs possess high educational attainment, one 
should expect creative class jobs to follow highly educated people. From a residential location perspective, access to interesting jobs is important. To the extent that jobs that are interesting to highly educated people are creative class jobs, highly educated people should be expected to follow creative class jobs. Therefore, simultaneity or bidirectionality is expected. A multisectoral framework also allows for other linkages, for example between people with and without higher education and between creative class jobs and other jobs. As noted by DE GRAAFF et al. (2012), the nature of these types of relationships is primarily an empirical issue. Failing to account for feedback in the estimation would bias the results while invalidating potential inferences and policy implications. Importantly, both human capital and creative class have potential roles to play.

\section{THE REGIONAL ADJUSTMENT MODEL}

The Carlino-Mills approach is a straightforward application of the partial adjustment model in a regional context where people and job trajectories are determined simultaneously. Partial adjustment models were developed in the econometric literature as early as in the 1950s (see LAMBERT et al., 2014). The empirical methodology applied can be summarized in three steps: 1. Estimate the spatial theoretical model by 2SLS using a non-spatial econometric model. 2. Test for spatial autocorrelation. 3. Retain the non-spatial econometric model if the null hypothesis of no spatial autocorrelation is not rejected; otherwise, consider a spatial econometric model. Our specification search methodology can therefore be described as a classical specific-to-general approach that is predominant in the applied spatial econometric literature (FLORAX et al. 2003). ${ }^{4}$

Regional studies using partial adjustment models have typically assumed that the lagged adjustment variables are exogenous. Little attention has been devoted to the possibility that lagged adjustment variables may be endogenous if the disturbances of the partial adjustment model are temporally correlated. LAMBERT et al. (2014) suggest using the GRILICHES (1967) common factor test to detect misspecification. In case of misspecification, that would call for instrumenting the lagged adjustment variables. ${ }^{5}$ The common factor test extended to the simultaneous partial adjustment model relevant for the regional adjustment model is presented in LAMBERT et al. (2014).

Exclusion restrictions on covariates that could assist in identification in the CarlinoMills framework are often questionable. Hence, one may have to rely on lagged endogenous variables for identification. The common factor test is then very useful as a check on instrument validity. Note that having data on only two points in time is sufficient to perform this test. Moreover, the specification used allows for the effects of the lagged dependent variables to differ across countries. This effectively means that the model is overidentified. Hence, one can use conventional overidentification tests for instrument validity.

To connect the present study to previous studies and thereby obtain some reference for whether the data generate results consistent with those found in the literature, the study now continues by examining the aggregate employment and total working age population for the economic regions under study, using the Carlino-Mills framework. The aggregate case may also serve as a reference for comparison for the within-sector dynamics in the multisectoral model.

The aggregate structural model to be estimated is, in principle, the following: 


$$
\begin{gathered}
\Delta p / T=\alpha_{0}+\alpha_{1} p_{-}+\alpha_{2} j+\mathbf{x}_{-} \alpha_{\mathbf{3}}+u_{p} \\
\Delta j / T=\beta_{0}+\beta_{1} j_{-}+\beta_{2} p+\mathbf{x}_{-} \beta_{3}+u_{j}
\end{gathered}
$$

Since we only consider two time periods, it is sufficient to mark initial values using subscript _. This version of the model, with growth rates as left-side variables, corresponds to the specification suggested by CLARK and MURPHY (1996). ${ }^{6}$ The left-side variables are average annual growth rates for people and jobs (change in natural logs over time divided by years). The right-side variables are the initial levels of the lefthand-side variable and current values of the potential endogenous variable (jobs in the people equation and people in the jobs equation, to be instrumented), and initial conditions (the vector $\mathbf{x}_{-}$). All variables except for dummies are measured in natural logs and relative to national averages (location quotients). ${ }^{7}$ The last term in each equation represents a conventional stochastic error term. As noted by CLARK and MURPHY (1996), a positive $\alpha_{2}$ in equation (1) provides direct evidence for People follow Jobs and a positive $\beta_{2}$ in equation (2) for Jobs follow People. Moreover, stability of the theoretical model requires conditional convergence: a negative and fractional $\alpha_{1}\left(\beta_{1}\right)$ in equation (1) (equation (2)).

The reduced form is given by

$$
\begin{aligned}
& p=a_{0}+a_{1} p_{-}+a_{2} j_{-}+\mathbf{x}_{-} \mathbf{a}_{3}+v_{p} \\
& j=b_{0}+b_{1} j_{-}+b_{2} p_{-}+\mathbf{x}_{-} \mathbf{b}_{3}+v_{j}
\end{aligned}
$$

Estimation of the reduced form is interesting for many reasons. First, the results can be interpreted directly as marginal effects measured as elasticities. Second and more importantly, by adding current value covariates and imposing zero value restrictions on $a_{2}$ and $b_{2}$, the reduced form permits testing the partial adjustment model against the serial correlation model. If the serial correlation hypothesis is rejected, the common practice in Carlino-Mills studies of using lagged adjustment variables as instruments is supported in the data and not only included on faith. Hence, the Griliches common factor test can assess instrument validity. Third, the relevance of the instruments is tested in the reduced-form regressions. A rule of thumb is that the $t$-value on the excluded instrument should exceed 3.2 (equivalent to an $F$-statistic above 10). Hence, a $t$-value below the threshold for $a_{1}$ in equation (3) suggests that the lagged value of $p$ is a weak instrument for $p$ in structural equation (2). A value below the threshold for $b_{1}$ in equation (4) suggests that the lagged value of $j$ is a weak instrument for $j$ in structural equation (1). ${ }^{8}$

After the initial analysis based on aggregate data, follows the analysis of the creative class within a multisectoral framework. The first sector, consisting of creative class jobs and people with higher education, is labeled 'Smart'. The second sector, consisting of 'non-creative' jobs and people without higher education, is labeled 'Main'. ${ }^{9}$ The framework allows for potential interdependence between Main and Smart. The multisectoral structural model equivalent to the aggregate structural model, using similar notation, may be written as ( $S$ for Smart, $M$ for Main) 


$$
\begin{aligned}
\Delta p^{S} / T & =\alpha_{0}^{S}+\alpha_{1}^{S} p_{-}^{S}+\alpha_{2}^{S} j^{S}+\mathbf{x}_{-} \alpha_{\mathbf{3}}^{\mathbf{S}}+\alpha_{4}^{S} j^{M}+\alpha_{5}^{S} p^{M}+u_{p}^{S} \\
\Delta j^{S} / T & =\beta_{0}^{S}+\beta_{1}^{S} j_{-}^{S}+\beta_{2}^{S} p^{S}+\mathbf{x}_{-} \beta_{\mathbf{3}}^{\mathbf{S}}+\beta_{4}^{S} j^{M}+\beta_{5}^{S} p^{M}+u_{j}^{S} \\
\Delta p^{M} / T & =\alpha_{0}^{M}+\alpha_{1}^{M} p_{-}^{M}+\alpha_{2}^{M} j^{M}+\mathbf{x}_{-} \alpha_{\mathbf{3}}^{\mathbf{M}}+\alpha_{4}^{M} j^{S}+\alpha_{5}^{M} p^{S}+u_{p}^{M} \\
\Delta j^{M} / T & =\beta_{0}^{M}+\beta_{1}^{M} j_{-}^{M}+\beta_{2}^{M} p^{M}+\mathbf{x}_{-} \beta_{\mathbf{3}}^{\mathbf{M}}+\beta_{4}^{M} j^{S}+\beta_{5}^{M} p^{S}+u_{j}^{M}
\end{aligned}
$$

The Jobs follow People and People follow Jobs hypotheses for the Smart sector could obviously be examined by concentrating on the first two relationships alone (equation 5 for People follow Jobs and 6 for Jobs follow People). However, that would have precluded an examination of other types of bidirectionality of substantial interest for dynamics of the Smart sector. There may, for example, be circular causation between Smart and Main jobs (examined by equations 6 and 8) or Smart and Main people (examined by equations 5 and 7 ).

\section{DATA}

The labor markets in the Nordic countries share several characteristics. Wage formation is influenced by strong trade unions and collective agreements. Wage dispersion is lower than in most other OECD countries, and the return to education is typically lower than in the U.S. and U.K. but roughly on par with the OECD average (OECD, 2014). Given the low dispersion of hourly wages, incentives for human capital formation in terms of education or migration seem to operate through occupational and spatial differences in employment probabilities and long-term career considerations rather than wage differences. Despite this, empirical findings indicate that the migration response to regional market disequilibria, patterns of internal migration, regional population growth and human capital clustering is similar to those in most other developed countries (BERCK et al., 2014).

This paper is not the first to study the creative class in the Nordic countries, but to the best of our knowledge, it is the first to use data that allow the study of dynamics. Prior work based on cross-sectional data, originating from the project 'Technology, Talent and Tolerance in European Cities: A Comparative Analysis', has been documented in a series of articles in refereed journals (see, e.g., BOSCHMA and FRITSCH 2009, ANDERSEN et al., 2010).

Cross-sectional analysis can only say something about level effects and not growth effects. The relevance of these studies is therefore not so much for comparing results as for sharing operational definitions of variables. For the purpose of international comparison across Europe in the project mentioned, ISCO-88 was employed to isolate professions at the three-digit level with the aim of following, as closely as possible, the creative class occupations originally used by FLORIDA (2002b). ${ }^{10}$ The occupations that were used to define the creative class may be placed in four groups: Bohemians, Creative professionals, Creative core and Creative core teachers. Creative core teachers and Bohemians were removed for reasons explained below.

As argued by MCGRANAHAN and WOJAN (2007), a premise of the works of Florida and followers is that the creative class is relatively footloose. Yet, some of the occupations used by BOSCHMA and FRITSCH (2009) are involved primarily in economic reproduction and provide essential services to a population. To correct for this, McGranahan and Wojan 'recast' the creative class and show that the results 
are sensitive to recasting, particularly for rural regions. By removing the Creative core teachers, the study aims to increase the conceptual validity of the creative class, following the recommendations of McGranahan and Wojan. ${ }^{11}$

FLORIDA (2002a) argues for bohemian occupations as an indicator of amenities. In his words, "This bohemian index is an improvement over previous measures of cultural and lifestyle amenities in that it represents a direct measure of the producers of cultural and creative assets. It also avoids the pitfalls of other measures which tend to be indirect measures of cultural assets (i.e. measure of cultural programming, art museums and galleries, or restaurants) and which draw distinctions between so-called high- low-culture." (p. 59) Following this suggestion, the bohemian index has been added as an amenity indicator in the people growth regressions. However, one could go further and argue that bohemianism is also an indicator of business attractiveness. The job growth regressions therefore also included the bohemian index. To avoid multicollinearity between the creative class variable and the bohemian index, the Bohemians were omitted from the creative class, following ANDERSEN et al. (2010). ${ }^{12}$ Following CARLINO and MILLS (1987), regional dummy variables that may capture natural amenities in the people growth regressions and first nature locational advantages in the job growth regressions were added. ${ }^{13}$

To control for possible national differences in conditional convergence rates, the model allows for interaction between the national dummies and initial values of the dependent variable (initial jobs (people) in the job (people) growth regressions). An added advantage of this is to allow for conventional testing for overidentification as an additional test for instrument validity even when there are no persuasive theoretical arguments for imposing exclusion restrictions on the covariates. If a common effect of the lagged dependent variable across the three countries had been imposed, the model would have been just identified by design and tests for overidentification would not have been feasible.

Data are for all economic regions at the former NUTS 4 level for Sweden (87), Norway (89), and Finland with exception of the Åland islands (74). The initial year is 2003 for Sweden and Norway and 2004 for Finland. The terminal year is 2008 for all three countries. ${ }^{14}$ Definitions of all variables used in the regression analysis are presented in Table A2 in the Appendix, where a more detailed discussion of operational variables and descriptive statistics (including a cartogram of creative class jobs) can be found.

\section{RESULTS}

First, the results for the structural form of the aggregate model are presented in Table 1 to provide a connection to the results reported in the literature on the issue of bidirectionality. The estimates for the reduced form are relegated to the Appendix (Table A4). Our main research questions are addressed in the estimation of the multisectoral model. These results are presented in Table 2 (structural form) and Table A5 (reduced form).

\section{The aggregate model}

Briefly reviewing the results of the meta analysis reported in HOOGSTRA et al (2005), the main conclusion from their analysis is that there is little overall support for bidirectionality. Their study is based on 308 estimates from 37 Carlino-Mills studies. Weight- 
ing the different results equally, the question of whether jobs follow people or people follow jobs remains largely unresolved. However, some studies report many more estimates than others. If the results receive less weight when they are obtained from studies reporting many rather than few estimates, the analyses suggest that jobs follow people. Interestingly, the indeterminacy in the absence of weighting appears to be driven primarily by the MULLIGAN et al. (1999) study. That study strongly suggests that people follow jobs and accounts for as much as 150 of the 308 estimates that constitute the sample for the meta-analysis.

How do our results compare to other studies? Direct evidence that people follow jobs is obtained by inspecting the parameter estimate for JD (Job Density) 2008 in the PD (People Density) growth equation. The parameter estimate is positive and precisely identified (first column, Table 1). The model diagnostics suggest the model performs reasonably well. ${ }^{15}$ Hence, the People follow Jobs hypothesis is corroborated. Similarly, direct evidence that jobs follow people is given by the estimate for PD 2008 in the JD growth equation. The estimate is not significantly different from zero (second column, Table 1). Hence, jobs do not appear to follow people.

[TABLE 1 HERE]

Summarized, the causality analysis based on aggregate data shows that our results are in line with most of the literature, suggesting one-way causation and not bidirectionality. Moreover, our results are in line with the MULLIGAN et al. (1999) results supporting the hypothesis that people follow jobs but not that jobs follow people.

Commenting on other results, the Cultural Amenities/Business Climate variable (the bohemian index) is positively related to growth both for people and jobs, as expected, and the Natural Amenities/First Nature Location Advantages (Regional Location) are significant (only joint significance is reported in Table 1 for brevity, but non-typical regions are suggested in Table A4 in the Appendix).

Other variables are important as control variables. The Urban variables (Capital Area and City Region), as well as Market Potential (Initial Population and Initial Accessibility), are positively related to PD growth but negatively related to JD growth. Greater industrial sector employment is positively related to JD growth but does not affect PD growth negatively (or at all).

\section{The multisectoral model}

For expository purposes, the within-sector and between-sector dynamics are distinguished when commenting on the estimation results from the multisectoral model. The within-sector dynamics may be compared to the aggregate dynamics. For the between-sector dynamics, there is no obvious reference for comparison. Structural estimates are reported in Table 2, and reduced-form estimates are relegated to Table A5 in the Appendix.

\section{Within-sector dynamics}

Do Smart jobs follow Smart people or do Smart people follow Smart jobs? The coefficient on the SPD (Smart People Density) 2008 variable in the SJD (Smart Job Density) growth model is positive, large, and highly significant. Furthermore, the SJD growth model performs well, passes all tests applied and is consistent with a stable underlying theoretical regional adjustment model. ${ }^{16}$ Because there are multiple endogenous regressors (as opposed to a single endogenous regressor in the aggregate model), 
the $F$-statistics are corrected as suggested by ANGRIST and PISCHKE (2009). The Angrist-Pischke $F$-statistics exceed 10 by a wide margin for all regressions ( $p$-values below 0.000). There is therefore no reason to not believe that the coefficient estimates can be given a causal interpretation. Therefore the conclusion is that Smart jobs follow Smart people. ${ }^{17}$

There is no evidence of reverse causality. The coefficient estimate on SJD 2008 in the SPD growth model (Table 2, 1st column) is not statistically significant. In addition, the results do not support a stable underlying theoretical adjustment model. The explained variance is low compared with the other regressions, leading us to believe that the model fails capturing what made Smart people choose their residential location in the early 2000s. Hence, even with a significant positive estimate, a causal interpretation could be called into question.

Turning to the Main sector, both the MPD (Main People Density) (Table 2, 3rd column) and the MJD (Main Job Density) (Table 2, last column) growth specifications perform well. No tests suggest that the model is misspecified. The estimates are consistent with stable underlying adjustment processes, although the convergence for MPD appears to be rather slow. As for the Smart sector, jobs seem to follow people. The coefficient estimate, however, is only half the size of that in the Smart sector and too small to be significant at more than the 10 percent level. ${ }^{18}$ People do not seem to follow jobs in the Main sector. Hence, in terms of within-sector dynamics, there is no qualitative difference between the sectors.

Summing up the within-sector causality analysis, there is one-way causation and not bidirectionality for each sector, similar to what was found based on aggregate data. Surprisingly, the within-sector causality moves in the opposite direction from what the aggregate model suggests. Jobs seem to follow people in both sectors, whereas people appeared to follow jobs based on the aggregate analysis. To understand how this is possible, it is necessary to account for the between-sector dynamics.

Let us also briefly comment on the non-adjustment variables in the multisectoral model. The Amenities/Business Climate variables seem to be less relevant than suggested in the aggregate analysis. The bohemian index remains positive and significant for MPD growth, as expected for a cultural amenity indicator, but not significant in the other regressions. The Regional Location variables remain jointly significant, except for the MJD growth regression. The Urban variables (Capital Area and City Region), and Market Potential (Initial Population and Initial Accessibility), remain positively related to PD growth and negatively related to JD growth. However, an exception can be noted for SJD growth, where Market Potential is ambiguous in the sense that Initial Population is positive and Initial Accessibility is negative (both statistically significant). Industry composition, positive and significant only in the aggregate job growth regression, is now positive and significant only in the MPD growth regression.

[TABLE 2 HERE]

\section{Between-sector dynamics}

The aggregate analysis suggests that people follow jobs. The disaggregate within-sector dynamics analysis suggests the opposite. This can hardly be reconciled without considering the interaction between sectors. Although all relevant information is provided in Table 2, the tabular presentation may be hard to read. To make the argument more transparent, only the statistically significant relevant estimates in the two key equations that explains the different results are presented in the equation below. 
Predicted value of the SPD growth rate, consistent with the notation in equation 5 , is equal to $.036 j^{M}-.024 p^{M}+$ other factors. Observe that although Smart people do not follow Smart jobs, they do follow Main jobs (point estimate .036, $t$-value 2.16). This essentially drives the aggregate result that people follow jobs, but why do Smart people follow Main jobs? This question is discussed further below.

Predicted value of the MJD growth rate, consistent with the notation in equation 8, is equal to $.025 p^{M}+.063 j^{S}-.029 p^{S}+$ other factors. Main jobs do to some extent follow Main people but the estimate is only significant at the 10 percent level (point-estimate $.025, t$-value 1.91). More importantly, Main jobs are deterred by Smart people and the effect is precisely identified (point estimate $-0.029, t$-value -3.47 ). On net, Main jobs do not follow people in general. This essentially drives the aggregate result that jobs do not follow people. But why are Main jobs deterred by Smart people?

One plausible answer to this that also provides a consistent answer to why Smart people follow Main jobs (the first question), is related to competing land use for residential and industrial purposes. This is reminiscent of what CARLINO and MILLS (1987) found for people and manufacturing employment (analysed separately in addition to the aggregate data). Observe in particular that they found that population deters manufacturing employment (their Table 4 first entry, second column). The interpretation offered is that because manufacturing is land intensive, the siting of manufacturing is deterred by the higher cost of land in densely populated areas (p. 50). The result is similar for Main jobs: Smart people deter Main jobs. The explanation for this seemingly counter-intuitive result could very likely be that suggested by Carlino and Mills 30 years ago. The argument is even stronger because it is not the density of poorly educated (Main people) with, on average, low income but the density of the relatively well educated (Smart people), with generally high income and high willingness/ability to bid up residential property prices, that has a deterring effect reflected in our data. However, from another perspective, less densely populated areas with lower property prices affordable for siting of Main jobs, also offer an opportunity for more affordable housing. Hence, there may be a tendency for people to follow Main jobs, not for employment opportunities, but for property that is less expensive. Taken together, our data are consistent with a story where Smart people relocate to areas where property prices are low and affordable. Increased pressure on land leads to Main jobs leaving the area until a new equilibrium is established with higher property prices, higher population density and lower density of Main jobs.

It is also interesting that Main jobs follow Smart jobs and vice versa. An analysis based on aggregates misses the strong circular causation between job creation in different sectors and is unable to capture such processes, as suggested long ago by HIRSCHMAN (1958) in a discussion of development strategies based on demand and supply linkages between firms.

To the best of our knowledge, there are only two other studies using a Carlino-Mills approach applied to Nordic data (SÖRENSSON, 2012 and TERVO, 2016). Common to these studies and ours is the result that people follow jobs at an aggregate level. Tervo, using data for Finland on the same spatial level, find no reverse causality. Sörensson, on the other hand, find reverse causality using data for administrative regions (municipalities) in Sweden. None of these studies use a multisectoral framework, but Tervo runs some regressions with highly educated instead of plain working age population. Interestingly, he then finds that jobs follow people instead of people following jobs. To the extent that the study by Tervo and ours are comparable, the two studies therefore seem to be in total agreement.

Our results may also be compared to DE GRAAFF et al. (2012). They suggest that 
population growth is largely exogenous and not driven by employment changes. Moreover, jobs appear to follow people in the retail, government, education and health sectors. In industry and other sectors, the dynamics appear to be driven by intersectoral linkages, i.e., jobs appear to follow jobs. Employing a non-standard sectoral classification that cuts across standard sectoral classifications at a more aggregate level (dichotomy instead of 49 sectors) and a division of people according to educational attainment (high/moderate (Smart) and low (Main)), the results are not directly comparable. It is nevertheless interesting that jobs appear to follow people in the Smart sector (similar to the retail, government, education and health sectors in the Dutch study) and that jobs appear to follow jobs in both the Smart and the Main sectors (similar to industry and many other sectors in the Dutch study). Main people dynamics appear largely exogenous (similar to people dynamics in the Dutch study), whereas the dynamics appear to differ for different groups when distinguishing between different levels of educational attainment (Smart and Main).

\section{CONCLUDING DISCUSSION}

As noted by DE GRAAFF et al. (2012), the only other empirical study to date based on a multisectoral regional adjustment model, it is remarkable that structural adjustment models describing the spatio-temporal dynamics of population and employment growth have not included intersectoral economic dynamics. This paper uses a multisectoral regional adjustment model to assess potential circular causation by testing the hypothesis that 'People follow Jobs' against 'Jobs follow People', in addition to 'Jobs follow Jobs' and 'People follow People'. The model distinguishes between the Smart sector (creative class jobs and people with higher education) and the Main sector (non-creative class jobs and people with lower education).

The regional adjustment framework leads to simultaneous equation models that are estimated with instrumental variable techniques because some of the regressors will be endogenous if the underlying theoretical model is correct. Our approach is to use the conventional non-spatial 2SLS estimator that appears to work well (no indication of spatial serial dependence in the residuals). This enables the use of ordinary tests for instrument validity and instrument weakness. The models also perform well in this respect.

On the aggregate level, there is support for the hypothesis that People follow Jobs but not for Jobs follow People. Short of a more disaggregate analysis, this suggests that economic development policies targeting regional growth should encourage the creation of work, whereas there is no support for investing in programmes making a place more attractive to live. However, when allowing for a richer analysis within a multisectoral model, this simple policy suggestion must be qualified.

Distinguishing between the Smart sector and the Main sector, the data supports Jobs follow People and not People follow Jobs (as suggested by the aggregate analysis). In the Smart sector, the effect appears to be large. ${ }^{19}$ In the Main sector, the effect seems to be smaller and less precisely identified.

This suggests that development policies should promote a location's attractiveness as a place for people to live, particularly people in the Smart sector. This would come as no surprise to many urban economists. However, targeting specifically people in the Smart sector could prove to be costly. Policies favouring an already privileged social group pose potentially serious negative consequences for the legitimacy of the social contract between social groups. As noted by STORPER and SCOTT (2009, p. 165), 
policy advocacies focused on investment in upscale amenities that primarily appeal to highly educated and high-income individuals 'largely ignore the urban economic and social divide, and, in practice, may well contribute to its exacerbation.'

The between-sector dynamics suggest that more general growth management policies than just investing in upscale amenities are relevant. Land use regulations may have unintended development effects. BOARNET et al. (2011), applying a CarlinoMills framework to counties in Florida, show that Florida's growth management program may have caused lower (higher) population equilibrium density and slower (faster) adjustment in urban (suburban) counties. Our data are consistent with a development towards lower (higher) Smart people equilibrium density in regions with low (high) Main jobs density. One possible interpretation is that people and jobs relocate in response to property prices. However, property prices are heavily depending on regulations that may speed up or slow down the adjustment processes. It is therefore of interest to look at land use regulation programs from a regional development perspective.

There is also strong bidirectional causality between jobs in the two sectors. Main jobs follow Smart jobs, and Smart jobs follow Main jobs. It would also be interesting to know whether there is a difference between different types of Main jobs conditional on land intensity. Unfortunately, no data that categorise main jobs according to land intensity are available. However, a consistent story suggests that land intensive Main jobs do not follow Smart jobs and that an attractive development policy could be to target job creation in the Smart sector in general and in the Main sector with low land intensity. Observe that the strong bidirectionality between Main jobs and Smart jobs will reinforce an initial stimulus through circular causation working through input-output linkages that are substantially important, as assessed by the size of the estimated effects. $^{20}$

Endogenous processes may therefore be important in assisting policy makers in making regional development policies more powerful by playing on circular and cumulative causation, not through linkages between labour demand and labour supply that appear to be less important or non-existing, but through input-output linkages between firms, as suggested by HIRSCHMAN (1958).

Encouraging growth induced by labour supply in the Smart sector, consistent with what has been advocated by Florida and others, also appears to have a substantial effect, but the between-sector analysis suggests that this type of policy does not trigger the sort of endogenous processes found for traditional labour demand policies. Importantly, our data are also consistent with a story where land use regulation may play an important role through intentional and unintentional regional development effects.

Finally, let us stress that the policy suggestions should be viewed as preliminary. Further studies, based on multisectoral frameworks, are needed to offer credible and robust policy advice. Fortunately, such contributions are likely forthcoming as new data increasingly become available.

\section{Acknowledgements}

Preliminary drafts have been presented at various regional science conferences in Europe (ERSA, Uddevalla) and America (WRSA). We would like to thank the participants for comments and suggestions. We would also like to thank the editor and the referees for their comments that have greatly improved the paper. The usual disclaimer applies. 


\section{Disclosure statement}

No potential conflict of interest was reported by the authors.

\section{Funding}

The reasearch for this article has in part been funded through grants from Sparebanken Nord-Norges Gavefond (project A38018), the Swedish Research Council (FORMAS grant no. 251-2007-2079), and the Strategic Research Council at the Academy of Finland (grant no. 303552).

\section{Notes}

\footnotetext{
${ }^{1}$ There is a large empirical literature related to the creative class, mostly microstudies based on crosssectional survey data. Recent examples include FAGGIAN et al. (2013), KRABEL and FLÖTHER (2014), and MARINELLI (2013).

${ }^{2}$ See GLAESER (2005) for a discussion on human capital versus creative class.

3 According to the International Labour Organization (ILO), "ISCO is a tool for organizing jobs into a clearly defined set of groups according to the tasks and duties undertaken in the job." Therefore, the concept is explicitly tied to the job and not to the person who happens, for the present, to be performing the tasks that define the occupation. A good discussion of the principles underlying ISCO can be found in ELIAS (1997).

${ }^{4}$ There is no consensus on whether 'specific-to-general' should be preferred to 'general-to-specific'. A defense of the former is provided by FLORAX et al. (2003) (see also HENDRY, 2006, and FLORAX et al. 2006), whereas ELHORST (2010) argues for the latter.

${ }^{5}$ The logic behind the test is outlined in the Appendix.

${ }^{6}$ The Carlino-Mills and Clark-Murphy specifications are compared and discussed in detail by MULLIGAN et al. (1999).

${ }^{7}$ Using logs and densities may mitigate problems that could arise from heteroscedasticity (CARRUTHERS and MULLIGAN., 2008, LAMBERT et al., 2014). We follow ANDERSEN et al. (2010) in using national averages as reference points for the location quotients rather than the average for the Nordic countries, since the economies are not fully integrated.

${ }^{8}$ MURRAY (2006) and BOLLEN (2012), provide good non-technical discussions of instrument validity and instrument relevance (instrument weakness). GIBBONS and OVERMAN (2012) provide a more technical critique of instrumental variable approaches in the spatial econometric literature.

${ }^{9}$ In the aftermath of the financial crisis, there was a heated public debate on the alleged favoring of 'Wall Street' at the expense of 'Main Street'. By analogy, we may consider 'Main' as a shorthand for the suggestive 'Main Street' term, and 'Smart' as a shorthand for 'Smart Street' (it would be nice if there were a real street called 'Smart' in Silicon Valley or some other iconic location - unfortunately, the only 'Smart Street' we know of is in Detroit).

${ }^{10}$ The list of occupations is for convenience reproduced in the Appendix.

${ }^{11}$ Our results for the Smart sector turn out to be sensitive to this recasting. To test whether it made a difference, we did estimate the multisectoral model also without recasting and got less precise estimates.

${ }^{12}$ See also ERIKSSON et al. (2014) for a recent discussion of indicators of business and people climate.

${ }^{13}$ We have used NUTS 2 dummies for Norway and Sweden. For Finland the NUTS 2 level is too aggregated to make sense. A spatial resolution more in line with the NUTS 2 division for the other countries, was obtained by using former Provinces from 1997 (five regions excluding Åland). See Table A2 in the Appendix for a list of the regions.

${ }^{14}$ Hence, the panel is balanced, but not strongly balanced. Both 2003 and 2004 were years of economic expansion in Finland and the effect on annual average growth rates of replacing 2003 with 2004 data is probably small. In order to avoid data contaminated by the financial crisis, 2008 was chosen as terminal year although data for 2009 and 2010 were available. Recall also that the theoretical model is an adjustment model where adjustment is sluggish. This is similar to other long term economic growth models where 5-year intervals are more appropriate than annual data. See the discussion in PARTRIDGE and RICKMAN (1999).

${ }^{15}$ Details are relegated to the Appendix because of space constraints.

${ }^{16}$ In the preferred multisectoral model specification, we have not allowed the convergence rate to differ between all countries in all equations as we did in the aggregate model. In the preferred specification, we only allow one country to differ and only in the Smart sector. This parsimonous choice is based on testing for instrument redundancy as suggested by HALL and PEIXE (2003), subject to passing the tests for instrument validity.
} 
${ }^{17}$ According to Table 2 (2nd column), the point estimate is 0.056 ( $t$-value 5.52$)$. Specifically, this means that we predict that a one percentage point higher density of Smart people in a region relative to the national average would be preceded by a 5.6 percent higher annual growth rate of the density of Smart jobs in the region relative to average national growth, holding other factors constant.

${ }^{18}$ Point estimate $0.025, t$-value 1.91 .

19 MIGUÉLEZ and MORENO (2014), on the other hand, find that inventors are attracted by job opportunities rather than the other way around.

${ }^{20}$ This is consistent with positive intersectoral local multipliers as found in Sweden and the U.S. (MORETTI and THULIN, 2013). It can also be interpreted as offering some credibility to creative class jobs (but even main jobs) generating external effects which foster economic growth as discussed by, e.g., ABREU et al. (2012). 


\section{REFERENCES}

ABREU, M., FAGGIAN, A., COMUNIAN, R. and MCCANN, P. (2012) Life is short, art is long: the presistent wage gap between Bohemian and non-Bohemian graduates, Annals of Regional Science, 49, 305-321

ANDERSEN, K.V., HANSEN, H.K., ISAKSEN, A. and RAUNIO, M. (2010) Nordic city regions in the creative class debate - putting the creative class thesis to a test, Industry and Innovation, 17, 215-240

ANGRIST, J.D. and PISCHKE, J.-S. (2009) Mostly harmless econometrics: An empiricist's companion. Princeton University Press, Princeton, NJ.

BERCK, P., TANO, S. and WESTERLUND, O. (2016) Regional sorting of human capital the choice of location among young adults in Sweden, Regional Studies, 50, 757-770

BOARNET, M.G., MCLAUGHLIN, R.B. and CORRUTHERS, J.I. (2011) Does state growth management change the pattern of urban growth? Evidence from Florida, Regional Science and Urban Economics, 41, 236-252

BOLLEN, K.A. (2012) Instrumental variables in sociology and the social sciences, Annual Review of Sociology, 38, 37-72

BOSCHMA, R.A. and FRITSCH, M. (2009) Creative class and regional growth: empirical evidence from seven European countries, Economic Geography, 85, 391-423

CARLINO, G.A. and MILLS, E.S. (1987) The determinants of county growth, Journal of Regional Science, 27, 39-54

CARRUTHERS, J.I. and MULLIGAN, G.F. (2008) A locational analysis of growth and change in American metropolitan areas, Papers in Regional Science, 87, 155-171

CLARK, D.E. and MURPHY, C.A. (1996) Countywide employment and population growth: An analysis of the 1980s, Journal of Regional Science, 36, 235-256

DE GRAAFF, T., VAN OORT, F.G. and FLORAX, R.J.G.M. (2012) Regional population-employment dynamics across different sectors of the economy, Journal of Regional Science, 52, 60-84

ELHORST, J.P. (2010) Applied spatial econometrics: raising the bar, Spatial Economic Analysis, 5, 9-28

ELIAS, P. (1997) Occupational classification (ISCO-88): Concepts, nethods, reliability, validity and cross-national comparability. OECD Labour Market and Social Policy Occasional Papers, 20.

ERIKSSON, R.H., HANSEN, H.K. and LINDGREN, U. (2014) The Importance of Business Climate and People Climate on Regional Performance, Regional Studies, online: http://dx.doi.org/10.1080/00343404.2013.770140

FAGGIAN, A., COMUNIAN, R., JEWELL, S. and KELLY, S. (2013) Bohemian graduates in the UK: disciplines and location determinants of creative careers, Regional Studies, 47, 183-200

FLORAX, R.J.G.M., FOLMER, H. and REY, S.J. (2003). Specification searches in spatial econometrics: the relevance of Hendrys methodology, Regional Science and Urban Economics, 33, 557-579

FLORAX, R.J.G.M., FOLMER, H. and REY, S.J. (2006). A comment on specification searches in spatial econometrics: the relevance of Hendrys methodology: A reply, Regional Science and Urban Economics, 36, 300-308

FLORIDA, R. (2002a) Bohemia and economic geography, Journal of Economic Geography, 2, 55-71

FLORIDA, R. (2002b) The rise of the creative class. Basic Books, New York. 
GIBBONS, S. and OVERMAN, H.G. (2012) Mostly pointless spatial econometrics?, Journal of Regional Science, 52, 172-191

GLAESER, E.L. (2005) Review of Richard Florida's The rise of the creative class, Regional Science and Urban Economics, 35, 593-596

GRILICHES, Z. (1967) Distributed lags: A survey, Econometrica, 35, 16-49

HALL, A.R. and PEIXE, F.P.M. (2003) A consistent method for the selection of relevant instruments, Econometric Reviews, 22, 269-287

HENDRY, D.F. (2006) A comment on Specification searches in spatial econometrics: the relevance of Hendrys methodology, Regional Science and Urban Economics, 36, 309-312

HIRSCHMAN, A.O. (1958), Strategy of Economic Development. Yale University Press, New Haven.

HOOGSTRA, G.J., FLORAX, R.J.G.M. and VAN DIJK, J. (2005) Do 'jobs follow people' or 'people follow jobs'? A meta-analysis of Carlino-Mills studies. Paper for the 45th ERSA Congress, Amsterdam.

ILO (1988) ISCO: International standard classification of occupations. Geneva: ILO.

KRABEL, S. and FLÖTHER, C. (2014) Here today, gone tomorrow? Regional labour mobility of German university graduates, Regional Studies, 48, 1609-1627

LAMBERT, D.M., XU, W. and FLORAX, J.G.M. (2014) Partial adjustment analysis of income and jobs, and the growth regimes in the Appalachian region with smooth transition spatial process models, International Regional Science Review, 37, 328-364

MARINELLI, E. (2013) Sub-national graduate mobility and knowledge flows: An exploratory analysis of onward- and return-migrants in Italy, Regional Studies, 47, 1618-1633

MASSEY, D.S. (1990) Household strategies and the cumulative causation of migration, Population Index, 56, 3-26

MCGRANAHAN, D. and WOJAN, T. (2007) Recasting the creative class to examine growth processes in rural and urban communities, Regional Studies, 41, 197-216

MIGUÉLEZ, E. and MORENO, R. (2014) What attracts knowledge workers? The role of space and social networks, Journal of Regional Science, 54, 33-60

MOILANEN, M. (2010) Matching and settlement patterns: the case of Norway, Papers in Regional Science, 89, 607-623

MORETTI, E. and THULIN, P. (2013) Local multipliers and human capital in the Unites States and Sweden, Industrial and Corporate Change, 22, 339-362

MULLIGAN, G. F., VIAS, A.C. and GLAVAC, S.M. (1999) Initial diagnostics of a regional adjustment model, Environment and Planning A, 31, 855-876

MURRAY, M.P. (2006) Avoiding invalid instruments and coping with weak instruments, Journal of Economic Perspectives, 20, 111-132

MUTH, R.F. (1971) Migration: chicken or egg?, Southern Economic Journal, 57, 295-306

OECD (2014) Education at a Glance 2014: OECD indicators, OECD Publishing.

PARTRIDGE, M.D. and RICKMAN, D.S. (1999) Which comes first, jobs or people?

An analysis of the recent stylized facts, Economics Letters, 64, 117-123

SÖRENSSON, R. (2012) Population and employment location in Swedish municipalities 1994-2004, Annals of Regional Science, 48, 743-762

STEINNES, D.N. (1977) Do people follow jobs or do jobs follow people? A causality issue in urban economics, Journal of Urban Economics, 4, 69-79

STORPER, M. and SCOTT, A.J. (2009) Rethinking human capital, creativity and urban growth, Journal of Economic Geography, 9, 147-167

TERVO, H. (2016) Do people follow jobs or do jobs follow people? The case of 
Finland in an international context, Journal of Regional Analysis and Policy, 46, 95109 
Table 1. The Aggregate Model: Structural Form

\begin{tabular}{|l|c|c|}
\hline Variable: & $\begin{array}{c}\text { People Density (PD) } \\
\text { Growth Rate }\end{array}$ & $\begin{array}{c}\text { Job Density (JD) } \\
\text { Growth Rate }\end{array}$ \\
\hline Initial PD Swe & $-0.014(-2.57)^{* *}$ & \\
\hline Initial PD Nor & $-0.021(-3.42)^{* * *}$ & $-0.026(-1.55)$ \\
\hline Initial PD Fin & $-0.019(-3.46)^{* * *}$ & $-0.009(-0.52)$ \\
\hline Initial JD Swe & & $-0.015(-1.13)$ \\
\hline Initial JD Nor & & $0.008(0.53)$ \\
\hline Initial JD Fin & & \\
\hline PD 2008 & & $-0.031(-5.19)^{* * *}$ \\
\hline JD 2008 & $0.016(2.87)^{* * *}$ & $-0.008(-1.83)^{*}$ \\
\hline Capital Area & $0.004(2.30)^{* *}$ & $0.002(0.62)$ \\
\hline City Region & $0.005(4.94)^{* * *}$ & $-0.008(-3.19)^{* * *}$ \\
\hline Initial Population & $0.002(2.42)^{* *}$ & $0.006(2.53)^{* *}$ \\
\hline Initial Accessibility & $0.003(3.91)^{* * *}$ & $0.010(3.06)^{* * *}$ \\
\hline Initial Industry Composition & $-0.000(-0.65)$ & $1.98(0.010)$ \\
\hline Initial Bohemian Index & $0.002(2.11)^{* *}$ & \\
\hline$F$ Regions) & $3.72(0.000)$ & 0.457 \\
\hline Diagnostics & & $3.08(0.214)$ \\
\hline$R$ square & & $591.20(0.000)$ \\
\hline Hansen $J$ & 0.713 & $-0.043(0.966)$ \\
\hline$F$ (excl.instruments) & $4.12(0.128)$ & $-0.799(0.424)$ \\
\hline Moran's I Sweden & $85.37(0.000)$ & $-1.097(0.273)$ \\
\hline Moran's I Norway & $1.093(0.274)$ & \\
\hline Moran's I Finland & $0.191(0.849)$ & $-0.814(0.416)$ \\
\hline
\end{tabular}

Note: Number of observations 250. All explanatory variables (except for dummies): logarithms of location quotients relative to the national average. Point estimates with $t$-values in parenthesis based on robust standard errors. Statistical level of significance $(* * *=.01, * *=.05, *=.10)$. For Sweden, Capital Area corresponds to Stockholm LA region, and City Region to Linköping, Malmö-Lund, Göteborg, Örebro, Västerås, and Umeå. For Norway, "Osloregionen" (Capital Area) and "Andre storbyregioner" (City Region) as used by Isaksen (2005). For Finland, Helsingin seutukunta (Capital Area), and Turku, Pori, Tampere, Lahti, Lappeenranta, Kuopio, Joensuu, Jyväskylä, Vaasa, and Oulu (City Region). Regional variables for Sweden and Norway are at the NUTS 2 level, for Finland at the 1997 Province level. Joint F- tests for the Regional dummies and excluded instruments with $p$-values in parenthesis. The Hansen $J$ test is an over- identification test for instrument validity that is robust to heteroscedasticity ( $p$-value of instrument validity in parenthesis). The "Moran's $I$ " is the $z$-score with the $p$-value of no spatial autocorrelation in parenthesis (two- sided testing using a row-standardized binary distance based weight matrix that ensures all regions have at least one neighbour). 
Table 2. The Multisectoral Model: Structural Form

\begin{tabular}{|c|c|c|c|c|}
\hline Variable: & $\begin{array}{l}\text { Smart People } \\
\text { Density (SPD) } \\
\text { Growth Rate }\end{array}$ & $\begin{array}{l}\text { Smart Job Density } \\
\text { (SJD) Growth Rate }\end{array}$ & $\begin{array}{c}\text { Main People } \\
\text { Density (MPD) } \\
\text { Growth Rate }\end{array}$ & $\begin{array}{c}\text { Main Job Density } \\
\text { (MJD) Growth } \\
\text { Rate }\end{array}$ \\
\hline Initial SPD Swe/Nor & $-0.001(-0.08)$ & & & \\
\hline Initial SPD Fin & $-0.002(-0.29)$ & & & \\
\hline Initial SJD Swe/Fin & & $-0.076(-5.09)^{* * * *}$ & & \\
\hline Initial SJD Nor & & $-0.097(-8.08)^{* * *}$ & & \\
\hline Initial MPD & & & $-0.014(-2.69) * * *$ & \\
\hline Initial MJD & & & & $-0.068(-4.47) * * *$ \\
\hline SPD 2008 & & $0.056(5.52)^{* * *}$ & $0.005(1.72)^{*}$ & $-0.029(-3.47)^{* * *}$ \\
\hline SJD 2008 & $-0.012(-0.92)$ & & $-0.002(-0.51)$ & $0.063(5.02)^{* * *}$ \\
\hline MPD 2008 & $-0.024(-1.83)^{*}$ & $-0.030(-1.35)$ & & $0.025(1.91)^{*}$ \\
\hline MJD 2008 & $0.036(2.16)^{* *}$ & $0.060(2.25)^{* *}$ & $0.010(1.46)$ & \\
\hline Capital Area & $-0.002(-0.40)$ & $-0.023(-4.14)^{* * * *}$ & $0.003(1.32)$ & $-0.012(-2.00)^{* *}$ \\
\hline City Region & $0.006(2.52)^{* *}$ & $-0.010(-2.35) * *$ & $0.003(2.60)^{* *}$ & $-0.003(-0.94)$ \\
\hline Initial Population & $0.007(3.34) * * *$ & $0.009(2.95)^{* * *}$ & $0.000(0.25)$ & $-0.002(-1.15)$ \\
\hline Initial Acessibility & $0.004(1.90)^{*}$ & $-0.006(-2.11)^{* *}$ & $0.002(3.02)^{* * *}$ & $-0.004(-1.98) * *$ \\
\hline Initial Industry Comp & $-0.002(-1.31)$ & $0.001(0.49)$ & $0.001(2.03)^{* *}$ & $-0.001(-0.86)$ \\
\hline Initial Bohemian Index & $0.003(1.04)$ & $-0.000(-0.00)$ & $0.001(2.34)^{* *}$ & $0.003(1.17)$ \\
\hline$F$ (Regions) & $2.31(0.002)$ & $2.12(0.005)$ & $3.94(0.000)$ & $1.02(0.442)$ \\
\hline \multicolumn{5}{|l|}{ Diagnostics } \\
\hline$R$ square & 0.240 & 0.616 & 0.712 & 0.487 \\
\hline Hansen $J$ & $0.135(0.713)$ & $0.684(0.408)$ & $2.515(0.284)$ & $3.809(0.149)$ \\
\hline AP F(SPD 2008) & & 1221.66 & 348.40 & 443.41 \\
\hline AP $F($ SJD 2008) & 35.52 & & 31.21 & 51.20 \\
\hline AP F(MPD 2008) & 704.65 & 834.88 & & 687.22 \\
\hline AP $F($ MJD 2008) & 62.98 & 96.30 & 50.16 & \\
\hline Moran's I Sweden & $-0.755(0.451)$ & $0.186(0.852)$ & $0.055(0.956)$ & $-0.375(0.708)$ \\
\hline Moran's I Norway & $-1.361(0.173)$ & $0.072(0.942)$ & $-0.581(0.561)$ & $-0.070(0.945)$ \\
\hline Moran's I Finland & $-0.850(0.396)$ & $-1.040(0.298)$ & $-0.449(0.654)$ & $-0.719(0.472)$ \\
\hline
\end{tabular}

Note: 250 observations. The "AP $F$ (endogenous regressor)" is a statistic for instrument weakness with multiple endogenous regressors (the Angrist-Prischke $F$-statistic). Cfr. note to Table 1 for other clarifications. 


\section{Appendix}

\section{The partial adjustment model}

The CARLINO and MILLS (1987) approach is a straightforward application of the partial adjustment model in a regional context where people and job trajectories are determined simultanoeously. Let us briefly review the partial adjustment model with a single dependent variable as outlined in GRILICHES (1967). In doing so, we also describe the common factor test of partial adjustment versus simply serial correlation. Although until recently ignored within the Carlino-Mills framework, the test is very useful. Carlino-Mills studies typically assume that the lagged adjustment variable is exogenous. However, if the true model is not a partial adjustment model, but a serial correlation model, the lagged adjustment variable is endogenous and invalid as an instrument for the current value adjustment variable. The common factor test can discriminate between the two models and thereby lend credibility to the use of lagged adjustment variables as instruments (see BROWN et al., 2013, and LAMBERT et al., 2014).

Introducing some notation to make concepts more precise, the equilibrium value of the dependent variable is determined by a vector of covariates,

$$
y^{*}=\mathbf{x} \alpha+u
$$

Only a fixed fraction (equal to $1 / \gamma$ ) of the adjustment to equilibrium is taking place within a single time period,

$$
y-y_{-}=\gamma\left(y^{*}-y_{-}\right)
$$

Since we only consider two time periods, it is sufficient to mark initial values using subscript _. Substituting and rearranging, we obtain $y=\mathbf{x} \alpha \gamma+(1-$ $\gamma) y_{-}+\gamma u$. Hence, we have a reduced form equation,

$$
y=\mathbf{x a}+b y_{-}+v,
$$

that could simply be estimated by OLS since there will be no serial correlation in $v$ provided there was none in $u$.

However, assume the true model is not the partial adjustment model, but the serial correlation model,

$$
y=\mathbf{x} \alpha+u, u=\rho u_{-}+e
$$

As shown by GRILICHES (1967), we can discriminate between the two models by adding lagged covariates to the reduced form equation that we estimate,

$$
y=\mathbf{x a}+b y_{-}+\mathbf{x}_{-} \mathbf{c}+v
$$

and test the restriction, $\mathbf{a} b+\mathbf{c}=0$. If $\mathbf{a} b=\mathbf{c}$, the serial correlation model is corroborated and the partial adjustment model is not credible. 
Notice that it is sufficient with only two time periods to do this test as opposed to the Lagrange Muliplier test proposed by MCCLAIN and WOOLDRIDGE (1995) that needs longer time series. Moreover, in a simultaneous equation model with multiple partial adjustment equations (as in the Carlino-Mills framework), rejecting the serial correlation model lends credibility to using the lagged dependent variable as an instrument in the first stage regression when estimating the structural form by 2SLS.

\section{Data}

Data on creative class jobs were obtained from the statistical bureaus of the three countries. Let us move from west to east and begin by examining the data for Norway. The initial data on creative class jobs are from 2003 (3rd quarter). Whereas the 2003 data were the only cross section available for the European project, summarized in BOSCHMA and FRITSCH (2009), here we also have had access to data from (the 3rd quarter of) 2007, 2008, 2009, and most recently, 2010. Hence, we have temporal as well as cross sectional information. The downturn following the financial crisis suggests that we should avoid 2009 and 2010, and we decided to use the data from 2008 in addition to 2003 to obtain the longest possible time span before the crisis. The occupations defining different creative class categories (creative core, creative core teachers, creative professionals, and bohemians) are presented with ISCO-codes in Table A1.

Data are for the 89 economic regions that correspond to the former NUTS 4 level in Europe. The spatial units are reasonably consistent with the regional labourmarkets that we would want the spatial units to represent from a theoretical perspective. However, we acknowledge that regions may be heterogenous in ways that could affect results and have included two dummy variables (referred to as Urban variables) to control for this: one variable for regions that could be considered to be part of the extended labour market related to Oslo ("Capital Area") and a variable for regions with a city center exceeding a threshold ("City Region"). ${ }^{1}$

The data for Sweden and Finland have been constructed in a similar way. Again, we use data for labour market areas. For Sweden we use the 87 labour market areas from 2003 (in Sweden the areas are endogenously determined and change over time, but we ignore this and keep borders fixed in line with the rest of the sample). The data are from 2003 and 2008 as for Norway. For Finland we used 74 regions based on the 2008 map. Data for 2003 were not available, so we used 2004 data instead. As for Norway, we include Urban variables: a dummy variable for the Capital Area and a dummy variable for City Regions. ${ }^{2}$

Apart from the occupation data used to construct creative class jobs, the other main variable is residential (night) population. We are particularly interested in the population possessing above average human capital as measured by educational attainment and have isolated people with at least lower degree tertiary education according to the ISCED classification, i.e., 3-4 years. In the 
Table A1 Creative Class Occupations Occupations (ISCO code)

\begin{tabular}{|c|c|}
\hline & Occupations (ISCO code) \\
\hline \multirow[t]{10}{*}{ Creative core } & Physicists, chemists, and related professionals (211) \\
\hline & Mathematicians, statisticians, and related professionals (212) \\
\hline & Computer systems designers and computer programmers (213) \\
\hline & Architects, engineers and related professionals (214) \\
\hline & Life science professionals (221) \\
\hline & Health professionals (222) \\
\hline & College, university and higher teaching professionals (231) \\
\hline & Archivists, librarians and related professionals (243) \\
\hline & Social science and related professionals (244) \\
\hline & Public service administrative professionals (247) \\
\hline \multirow{4}{*}{ Creative core teachers } & Secondary education teaching professionals (232) \\
\hline & Primary and pre-primary education teaching professionals (233) \\
\hline & Special-education teaching professionals (234) \\
\hline & Other teaching professionals (235) \\
\hline \multirow[t]{15}{*}{ Creative professionals } & Legislators, senior officials, and managers (I) \\
\hline & Nursing and midwifery professionals (223) \\
\hline & Business professionals (241) \\
\hline & Legal professionals (242) \\
\hline & Engineering science technicians (311) \\
\hline & Computer associate professionals (312) \\
\hline & Optical and electronic equipment operators (313), except (3131) \\
\hline & Ship and aircraft controllers and technicians (314) \\
\hline & Fire and safety inspectors (315) \\
\hline & Life science and health associate professionals (32) \\
\hline & Finance and sales associate professionals (341) \\
\hline & Business services agents and employment agents (342) \\
\hline & Administrative and economic associate professionals (343) \\
\hline & Police officers (345) \\
\hline & Social workers (college-trained), child care officers, etc (346) \\
\hline \multirow[t]{4}{*}{ Bohemians } & Writers and creative or performing artists (245) \\
\hline & Photographers and image and sound recording \\
\hline & equipment operators ( 3131 ) \\
\hline & $\begin{array}{l}\text { Artistic, entertainment and sports associate professional } \\
\text { Fashion and other models }(521)\end{array}$ \\
\hline
\end{tabular}


literature, the adjustment variables have often been normalized by an areal metric to obtain population and employment densities. The most reasonable option in the context of topological heterogeneity and uninhabited hinterland is to consider built-up areas rather than total area (CARRUTHERS and MULLIGAN 2008; MOILANEN 2010). We did run some preliminary regressions using both gross area and built-up area. The results are qualitatively similar, but the point estimates are much larger (by a factor of 10) when using simple gross area. We report results based on built-up area.

There is unfortunately no consensus in the literature on control variables. The topic has been relegated to interesting but remaining research issues in the meta-analysis by HOOGSTRA et al. (2005), sampling from a large number of studies. However, we should at least acknowledge that there may be spatial processes at work apart from the interregional adjustment of jobs and people that need to be controlled for. Our approach in this respect is to include two variables that seen together may capture market potential. First, the size of the local economy as measured by initial population. Second, an accessibility indicator suggested by ELIASSON et al. (2003), measuring interregional accessibility or interregional leakage, depending on the perspective. ${ }^{3}$

Following common practice, we are also controlling for industry structure. CLARK and MURPHY (1996) makes a distinction between Industrial Sectors and Commercial Sectors. We make a similar distinction, but follow ESCRIBÁ and MURGUI (2013) that define Industrial Sectors as ESA-95 codes C (mining and quarrying), D (manufacturing), and E (electricity, gas and water supply). We introduce the share of employment in Industrial Sectors both in the job growth and people growth regressions. ${ }^{4}$

Variable definitions are presented in Table A2. Descriptive statistics are presented in Table A3 and in the cartogram (DORLING, 1995) in Figure A1. All variables are expressed as location quotients. Hence, the means of all variables are equal to unity by construction. Instead of reporting means, we therefore report medians in Table A3. In order to illustrate the regional distribution of creative class jobs we compare the cartogram to the ordinary map in Figure A1. Without going into details about each and every region, we observe a general pattern where creative jobs are overrepresented in the south and the capital areas in particular. ${ }^{5}$ The cartogram distorts the regional boundaries so that the area of each region is in proportion to the creative class job density location quotients for 2008. The different colors distinguish the three countries. It may be instructive to flip the perspective and view the ordinary map as a cartogram representing the hypothetical situation with creative class jobs equally distributed across regions, whereas the cartogram represent the real situation with the jobs clearly clustered. Perhaps the most striking visual difference is the almost disappearing of northern Sweden and Finland. The geography of creative jobs demonstrates the factual basis for political concern over the clustering of 'good' jobs, a legitimate concern and a motivation for research on this issue. 

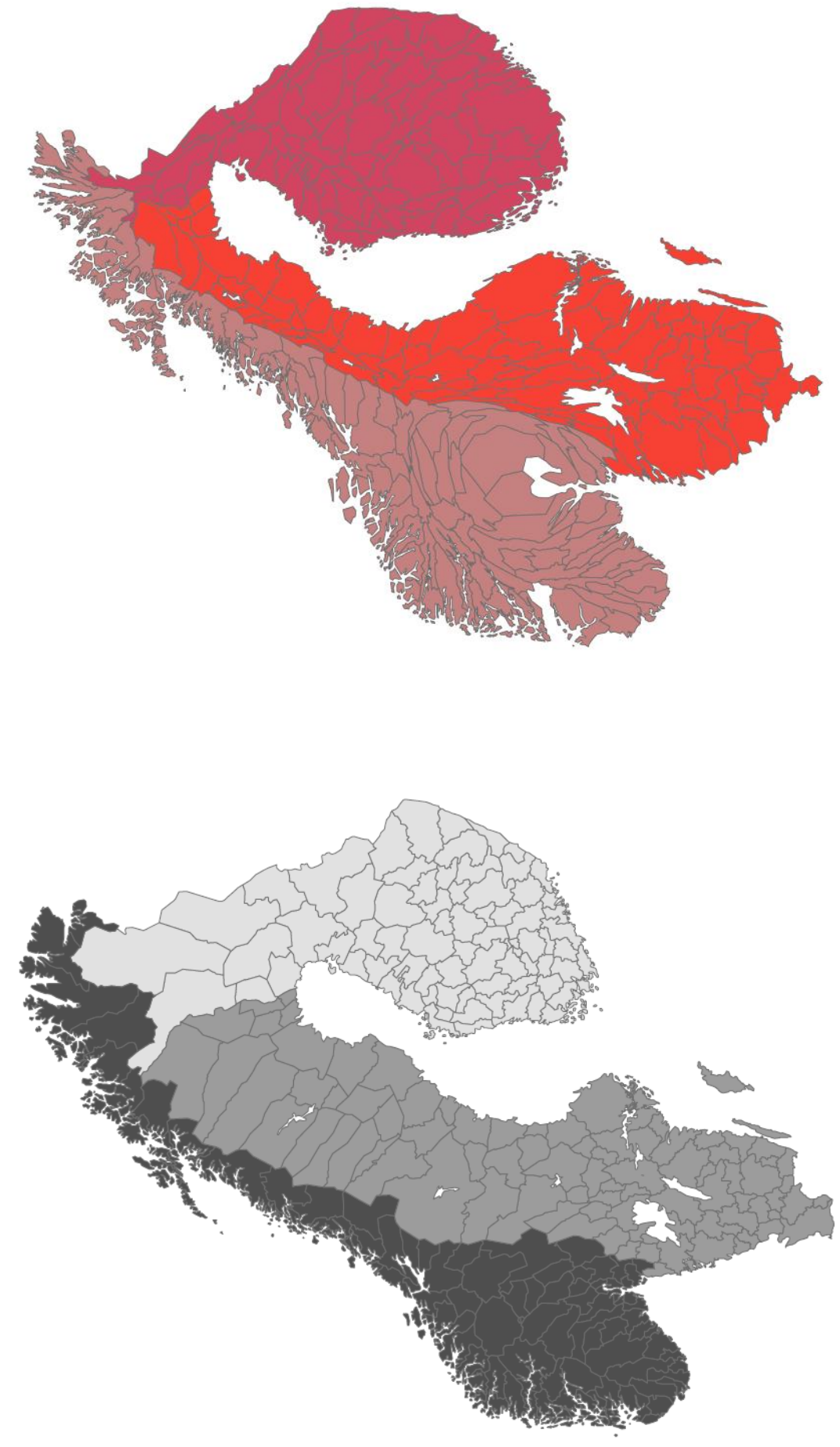

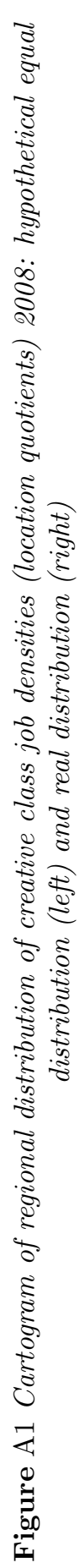


Table A2 Variable Definitions

$\begin{array}{ll}\text { People Density } & \text { Working age population/ Area } \\ \text { Main People Density } & \text { Working age population without higher education/ Area } \\ \text { Smart People Density } & \text { Working age population with higher education/ Area } \\ \text { Job Density } & \text { Employment/ Area } \\ \text { Smart Job Density } & \text { Creative core and professionals/Area } \\ \text { Main Job Density } & \text { Employment excl. Smart Jobs and bohemians/Area } \\ \text { Bohemian Job Density } & \text { Bohemians/ Area } \\ \text { Industry Composition } & \text { Initial employment for ESA-95 codes C (mining and quarrying), } \\ & \text { D (manufacturing), and E (electricity, gas and water supply) } \\ \text { Population } & \text { Total initial population } \\ \text { Accessibility } & \text { Distance weighted initial employment of other regions } \\ \text { Capital Area } & \text { Stockholm LA region; Oslo region (Oslo, Askim/Mysen, Follo, } \\ & \text { Bærum/Asker, Lillestrøm, Ullensaker/Eidsvoll, and Hadeland); } \\ & \text { Helsinki region } \\ & \text { Linköping, Malmö-Lund, Göteborg, Örebro, Västerås, and Umeå; } \\ \text { City Region } & \text { Bergen, Stavanger, Trondheim, Fredrikstad, Drammen, Grenland, } \\ & \text { Kristiansand, and Troms } \varnothing \text {;urku, Pori, Tampere, Lahti, } \\ & \text { Lappeenranta, Kuopio, Joensuu, Jyväskylä, Vaasa, and Oulu } \\ & \text { East Middle Sweden (SE11, SE12), Småland and Islands (SE21), } \\ \text { Regional dummies } & \text { South Sweden (SE22), West Sweden (SE23), North Middle } \\ & \text { Sweden (SE31), Middle Norrland (SE32), and Upper Norrland (SE33); } \\ & \text { Oslo and Akershus (NO01), North East Norway (NO02), South East } \\ & \text { Norway (NO03), South Norway (NO04), West Norway (NO05), } \\ & \text { Middle Norway (NO06), and North Norway (NO07); } \\ & \text { South Finland (FI13), West Finland (FI15), East Finland (FI14), } \\ & \text { Oulu (FI08), and Lapland (FI06) }\end{array}$

Note: Area is measured as build up area following CARRUTHERS and MULLIGAN (2008), and MOILANEN (2010). Industry composition is based on employment in industrial sectors following the definition in ESCRIBÁ and MURGUI (2013). Acessibility is defined as the indicator in ELIASSON et al. (2003). Regional variables for Sweden and Norway are at the NUTS 2 level, for Finland at the 1997 Province level. 


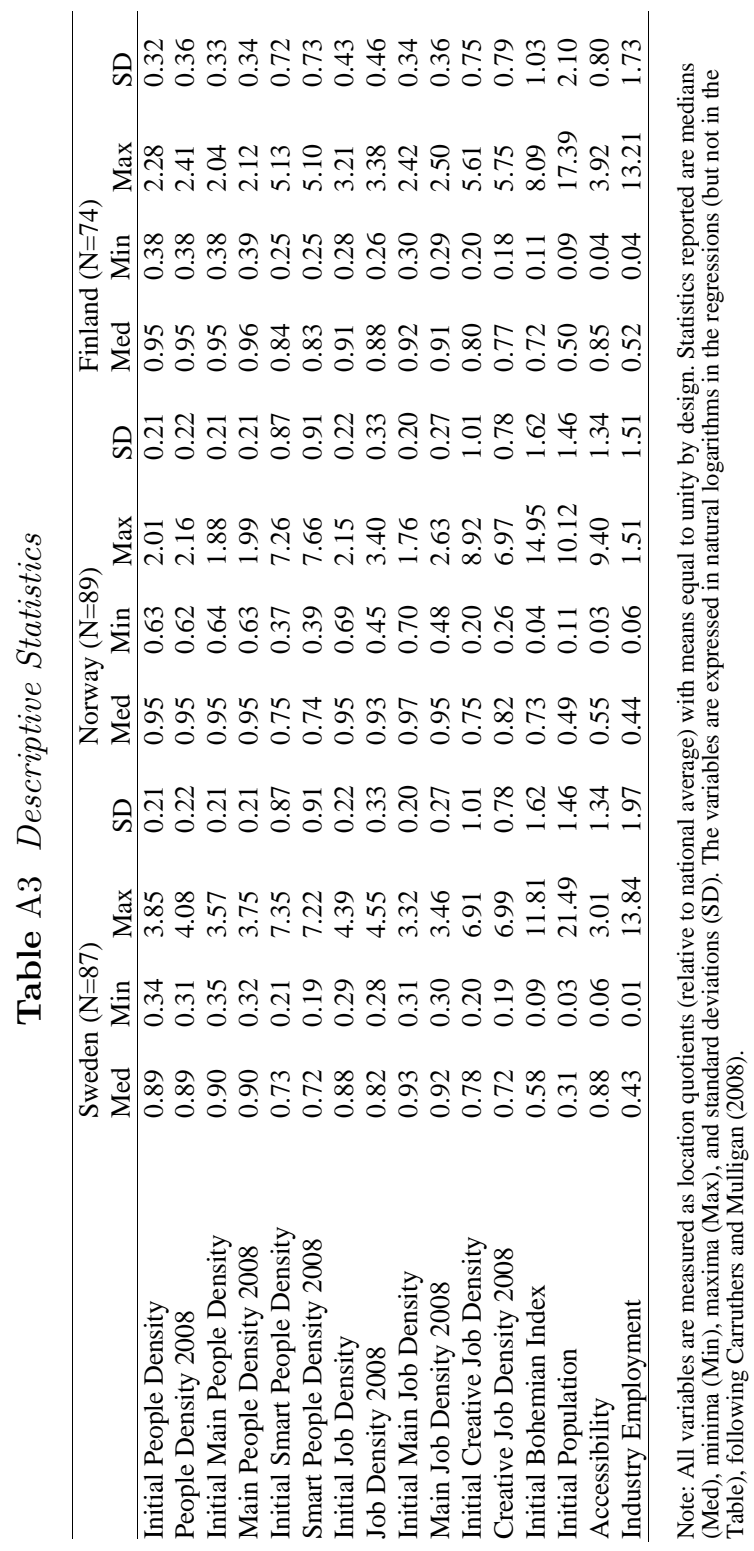




\section{Aggregate model performance}

How does the aggregate model perform? Our concern regarding instrument validity is evaluated by the Griliches Common Factor test and the Hansen $J$ test (similar to the Sargan test but robust to heteroscedasticity). The Griliches test is a test of the partial adjustment hypothesis that serves as a test of the validity of lagged dependent variables as instruments (reported in Table A4 ), whereas the Hansen $J$ test is a test for overidentifying restrictions that serves as a test for instrument validity (reported in Table 1 in the main text). We observe that both regressions pass these tests.

To detect instrument weakness, we rely on $F$ tests for excluded instruments in the first-stage regressions. An $F$-statistic exceeding approximately 10 is suggested as a rule of thumb for strong instruments (ANGRIST and PISCHKE, 2009). We observe that the statistics suggest that the model performs well with $F$-statistics exceeding 10 by a wide margin and $p$-values below 0.000 for both regressions.

Spatial autocorrelation in the residuals is evaluated by Moran's $I$ test using a binary-distance-based weighting matrix that ensures that all regions have at least one neighbour. The threshold distances therefore differ for the three countries: $113 \mathrm{~km}$ (Norway), $138 \mathrm{~km}$ (Sweden) and $169 \mathrm{~km}$ (Finland). The null of no autocorrelation in the residuals is not rejected in either of the two regressions. ${ }^{6}$

Turning to the stability of the underlying adjustment processes, we examine the conditional convergence rates. The parameters for Initial PD (People Density) for Sweden, Norway and Finland, reported in Table 1 in the main text (first column), are all negative and significantly less than zero but larger than negative one, as required for the conditional convergence and stability of the partial adjustment process. This is not the case for the partial adjustment of JD (Job Density). None of the parameters for Initial JD for Sweden, Norway and Finland (Table 1, second column) are significantly different from zero. Hence, there is no support for conditional convergence between regions (but not for divergence either). This difference suggests that demand and supply side

adjustments cannot be treated symmetrically, at least not for the sample period under study. 


\section{Reduced form estimates}

Reduced form estimates are reported in Table A4 (aggregate model) and A5 (multisectoral model). There are 250 observations in each regression. All explanatory variables (except for dummies) are measured as logarithms of location quotients relative to the national average. The tables give point estimates with t-values in parentheses based on robust standard errors. Statistical level of significance $\left(* * *=.01,{ }^{* *}=.05, *=.10\right)$. For Sweden, Capital Area corresponds to Stockholm LA region, and City Region to Linköping, Malmö-Lund, Göteborg, Örebro, Västerås, and Umeå. For Norway, Osloregionen (Capital Area) and Andre storbyregioner (City Region) as used by Isaksen (2005). For Finland, Helsingin seutukunta (Capital Area), and Turku, Pori, Tampere, Lahti, Lappeenranta, Kuopio, Joensuu, Jyväskylä, Vaasa, and Oulu. Regional variables for Sweden and Norway are at the NUTS 2 level (SE11 and SE12 merged to avoid perfect collinearity), for Finland at the 1997 Province level (FIPS PUB 10-4 codes (U.S. government standard)). Joint F-tests for the regional variables and lagged dependent variables. The Griliches Common Factor test is implemented as a joint Wald test (Wald statistic with p-value in parentheses). The Morans I is the z-score with the p-value of no spatial autocorrelation in parenthesis (two-sided testing using a row-standardized binary distance based weight matrix that ensures all regions have at least one neighbour). 
Table A4 The Aggregate Model: Reduced Form

\begin{tabular}{|c|c|c|}
\hline Variable: & People Density (PD) & Job Density (JD) \\
\hline Initial PD Swe & $0.985(24.00)^{* * *}$ & $0.191(1.68)^{*}$ \\
\hline Initial PD Nor & $0.780(14.83)^{* * *}$ & $-0.120(-0.50)$ \\
\hline Initial PD Fin & $0.929(31.28)^{* * *}$ & $-0.008(-0.13)$ \\
\hline Initial JD Swe & $0.027(0.72)$ & $0.744(7.02)^{* * *}$ \\
\hline Initial JD Nor & $0.195(3.93)^{* * *}$ & $1.113(4.94)^{* * *}$ \\
\hline Initial JD Fin & $0.050(1.84)^{*}$ & $0.959(15.65)^{* * *}$ \\
\hline Capital Area & $0.006(0.69)$ & $-0.160(-4.96)^{* * *}$ \\
\hline City Region & $0.020(4.63)^{* * *}$ & $-0.043(-2.08)^{* *}$ \\
\hline Initial Population & $0.008(2.71)^{* * *}$ & $0.010(0.81)$ \\
\hline Initial Accessibility & $0.013(3.42)^{* * *}$ & $-0.037(-2.75)^{* * *}$ \\
\hline Initial Industry Composition & $0.000(0.10)$ & $0.025(2.04)^{* *}$ \\
\hline Initial Bohemian Index & $0.010(3.37)^{* * *}$ & $0.048(2.89)^{* * *}$ \\
\hline East Middle Sweden (SE11, SE12) & $-0.012(-1.93)^{*}$ & $0.049(2.51)^{* *}$ \\
\hline Småland \& Islands (SE21) & $0.011(1.49)$ & $0.041(2.44)^{* *}$ \\
\hline South Sweden (SE22) & $0.006(1.17)$ & $0.050(2.85)^{* * *}$ \\
\hline West Sweden (SE23) & $0.020(3.27)^{* * *}$ & $0.004(0.33)$ \\
\hline North Middle Sweden (SE31) & $-0.001(-0.27)$ & $0.003(0.28)$ \\
\hline Middle Norrland (SE32) & $-0.005(-0.68)$ & $-0.026(-1.58)$ \\
\hline Upper Norrland (SE33) & $-0.003(-0.38)$ & $0.004(0.15)$ \\
\hline Oslo \& Akershus (NO01) & $0.015(0.77)$ & $0.215(1.95)^{*}$ \\
\hline North East Norway (NO02) & $-0.006(-1.11)$ & $-0.015(-0.64)$ \\
\hline South East Norway (NO03) & $0.000(0.01)$ & $0.006(0.24)$ \\
\hline South Norway (NO04) & $0.026(6.12)^{* * *}$ & $0.024(1.06)$ \\
\hline West Norway (NO05) & $0.006(0.99)$ & $0.029(1.59)$ \\
\hline Middle Norway (NO06) & $0.025(3.14) * * *$ & $0.024(1.06)$ \\
\hline North Norway (NO07) & $0.029(2.95)^{* * *}$ & $-0.008(-0.32)$ \\
\hline South Finland (FI13) & $0.011(1.66)^{*}$ & $0.033(1.93)^{*}$ \\
\hline West Finland (FI15) & $0.005(1.11)$ & $0.034(3.08)^{* * *}$ \\
\hline East Finland (FI14) & $-0.005(-1.03)$ & $0.001(0.04)$ \\
\hline Oulu (FI08) & $0.021(2.26)^{* *}$ & $0.021(1.59)$ \\
\hline Lapland (FI06) & $0.014(1.10)$ & $-0.032(-1.16)$ \\
\hline \multicolumn{3}{|l|}{ Diagnostics } \\
\hline$R$ square & 0.998 & 0.982 \\
\hline Griliches Common Factor & $85.85(0.000)$ & $85.48(0.000)$ \\
\hline$F$ (Regions) & $4.31(0.000)$ & $2.01(0.009)$ \\
\hline$F$ (lagged dependent variable) & $591.20(0.000)$ & $85.37(0.000)$ \\
\hline Moran's I Sweden & $0.657(0.511)$ & $-0.058(0.953)$ \\
\hline Moran's I Norway & $-0.945(0.345)$ & $-1.128(0.259)$ \\
\hline Moran's I Finland & $-0.795(0.427)$ & $-1.583(0.113)$ \\
\hline
\end{tabular}


Table A5 The Multisectoral Model: Reduced Form

\begin{tabular}{|c|c|c|c|c|}
\hline Variable: & $\begin{array}{c}\text { Smart People } \\
\text { Density (SPD) }\end{array}$ & $\begin{array}{c}\text { Smart Job Density } \\
\text { (SJD) }\end{array}$ & $\begin{array}{c}\text { Main People } \\
\text { Density (MPD) }\end{array}$ & $\begin{array}{c}\text { Main Job Density } \\
\text { (MJD) }\end{array}$ \\
\hline Initial SPD Swe/Nor & $0.969(51.48)^{* * *}$ & $0.252(5.29)^{* * * *}$ & $0.016(1.71)$ & $-0.053(-2.08) * *$ \\
\hline Initial SPD Fin & $0.962(39.67)^{* * *}$ & $0.273(4.86)^{* * * *}$ & $0.006(0.44)$ & $-0.038(-1.21)$ \\
\hline Initial SJD Swe/Fin & $-0.020(-0.53)$ & $0.649(8.38)^{* * * *}$ & $0.008(0.50)$ & $0.152(3.59)^{* * *}$ \\
\hline Initial SJD Nor & $0.006(0.21)$ & $0.578(10.20)^{* * *}$ & $-0.000(-0.01)$ & $0.203(5.25)^{* * *}$ \\
\hline Initial MPD & $-0.072(-1.55)$ & $-0.102(-0.99)$ & $0.939(43.61)^{* * *}$ & $0.099(1.72)$ \\
\hline Initial MJD & $0.120(2.52)^{* * *}$ & $0.236(2.44)^{* * *}$ & $0.032(1.43)$ & $0.769(13.82)^{* * *}$ \\
\hline Capital Area & $-0.013(-0.78)$ & $-0.147(-5.08)^{* * *}$ & $0.010(0.96)$ & $-0.091(-2.90)^{* * * *}$ \\
\hline City Region & $0.023(2.38)^{* *}$ & $-0.060(-2.70)^{* * *}$ & $0.014(2.76)^{* * * *}$ & $-0.033(-2.35)^{* *}$ \\
\hline Initial Population & $0.031(3.30)^{* * * *}$ & $0.043(2.45)^{* * *}$ & $0.002(0.62)$ & $-0.007(-0.60)$ \\
\hline Initial Accessibility & $0.012(1.56)$ & $-0.038(-2.71)^{* * * *}$ & $0.010(2.87)^{* * *}$ & $-0.033(-3.45)^{* * *}$ \\
\hline $\begin{array}{l}\text { Initial Industry } \\
\text { Composition }\end{array}$ & $-0.011(-1.24)$ & $0.012(0.64)$ & $0.003(1.08)$ & $0.003(0.37)$ \\
\hline Initial Bohemian Index & $0.014(1.22)$ & $0.007(0.26)$ & $0.008(2.86)^{* * * *}$ & $0.012(1.17)$ \\
\hline $\begin{array}{l}\text { East Middle Swe (SE11, } \\
\text { SE12) }\end{array}$ & $-0.000(-0.02)$ & $0.061(3.27)^{* * * *}$ & $-0.003(-0.54)$ & $0.025(1.45)$ \\
\hline Småland \& Islands (SE21) & $0.031(2.36)^{* *}$ & $0.063(2.89)^{* * * *}$ & $0.008(1.33)$ & $0.022(1.22)$ \\
\hline South Swe (SE22) & $0.026(2.60)^{* *}$ & $0.071(2.47)^{* * *}$ & $0.004(0.89)$ & $0.022(1.61)$ \\
\hline West Swe (SE23) & $0.034(2.68)^{* * * *}$ & $-0.013(-0.45)$ & $0.015(3.27)^{* * * *}$ & $-0.003(-0.16)$ \\
\hline North Middle Swe (SE31) & $-0.010(-1.10)$ & $0.006(0.33)$ & $0.004(0.96)$ & $-0.008(-0.64)$ \\
\hline Middle Norrland (SE32) & $-0.026(-1.21)$ & $-0.049(-1.96)^{*}$ & $-0.002(-0.39)$ & $-0.041(-2.41)^{* *}$ \\
\hline Upper Norrland (SE33) & $-0.025(-1.06)$ & $-0.047(-1.14)$ & $0.001(0.07)$ & $-0.021(-0.79)$ \\
\hline Oslo \& Akershus (NO01) & $-0.001(-0.04)$ & $-0.047(-0.49)$ & $0.019(0.81)$ & $0.089(0.90)$ \\
\hline North East Nor (NO02) & $-0.043(-3.04)^{* * * *}$ & $-0.031(-0.92)$ & $-0.004(-1.07)$ & $0.014(0.58)$ \\
\hline South East Nor (NO03) & $-0.046(-2.28)^{* *}$ & $-0.021(-0.68)$ & $0.003(0.53)$ & $0.012(0.62)$ \\
\hline South Nor (NO04) & $0.039(2.54)^{* *}$ & $0.023(0.55)$ & $0.027(4.71)^{* * *}$ & $0.033(1.90)^{*}$ \\
\hline West Nor (NO05) & $0.014(0.99)$ & $0.107(2.29)^{* * *}$ & $0.005(0.82)$ & $0.012(0.91)$ \\
\hline Middle Nor (NO06) & $0.040(1.60)$ & $0.080(1.37)$ & $0.023(2.93)^{* * *}$ & $0.036(1.43)$ \\
\hline North Nor (NO07) & $0.046(1.58)$ & $0.093(1.66)^{*}$ & $0.019(1.96)^{*}$ & $-0.043(-1.71)^{*}$ \\
\hline South Fin (FI13) & $-0.004(-0.39)$ & $0.003(0.22)$ & $0.011(1.73)^{*}$ & $0.029(1.75)^{*}$ \\
\hline West Fin (FI15) & $-0.001(-0.09)$ & $0.033(2.18)^{* *}$ & $0.006(1.51)$ & $0.026(2.87)^{* * *}$ \\
\hline East Fin (FI14) & $-0.011(-1.04)$ & $-0.025(-1.11)$ & $-0.005(-1.12)$ & $-0.020(-1.45)$ \\
\hline Oulu (FI08) & $0.024(1.08)$ & $0.040(1.67)^{*}$ & $0.022(2.62) * * *$ & $-0.008(-0.54)$ \\
\hline Lapland (FI06) & $0.017(0.69)$ & $-0.056(-1.50)$ & $0.011(1.00)$ & $-0.060(-2.39)^{* *}$ \\
\hline$F$ (Regions) & $2.28(0.002)$ & $2.81(0.000)$ & $4.01(0.000)$ & $1.57(0.065)$ \\
\hline \multicolumn{5}{|l|}{ Diagnostics } \\
\hline$R$ square & 0.994 & 0.976 & 0.998 & 0.980 \\
\hline Griliches Common Factor & $28.30(0.000)$ & $47.53(0.000)$ & $62.75(0.000)$ & $70.75(0.000)$ \\
\hline$F$ (lagged dep. variable) & $1326.83(0.000)$ & $53.34(0.000)$ & $1902.08(0.000)$ & $190.91(0.000)$ \\
\hline Moran's I Sweden & $-0.870(0.384)$ & $0.513(0.608)$ & $0.028(0.978)$ & $0.111(0.912)$ \\
\hline Moran's I Norway & $-1.562(0.118)$ & $0.069(0.945)$ & $-0.711(0.477)$ & $-0.560(0.576)$ \\
\hline Moran's I Finland & $-1-018(0.309)$ & $-0.993(0.321)$ & $-0.774(0.439)$ & $-0.235(0.815)$ \\
\hline
\end{tabular}




\section{Notes}

${ }^{1}$ We follow ISAKSEN (2005), giving details and background for the Norwegian contribution to the European project referred to previously. The Capital Area dummy is assigned to Oslo, Askim/Mysen, Follo, Bærum/Asker, Lillestrøm, Ullensaker/Eidsvoll, and Hadeland. The City Region dummy is assigned to Bergen, Stavanger, Trondheim (incl. Stjørdalshalsen), Fredrikstad, Drammen (incl. Holmestrand and Sande/Svelvik), Grenland, Kristiansand (incl. Lillesand), and Troms $\varnothing$.

${ }^{2}$ Capital Area (Stockholm LA region and Helsingin seutukunta). City regions Sweden: Linköping, Malmö-Lund, Göteborg, Örebro, Västerås, Umeå; Finland: Turku, Pori, Tampere, Lahti, Lappeenranta, Kuopio, Joensuu, Jyväskylä, Vaasa, Oulu.

${ }^{3}$ We are grateful to Kent Eliasson at the Swedish Agency for Growth Policy Analysis for assistance with accessibility and population density data for Sweden.

${ }^{4}$ Although industry composition may be most relevant as a control in the job growth regression, we cannot rule out that industry composition also directly affects people growth through for example environmental effects that people care about.

${ }^{5}$ This may not come as a surprise as the pattern appears for many countries. HUGGINS and CLIFTON (2011), for example, suggest a location quotient for London about 1.3 for creative class jobs (not normalized by area).

${ }^{6}$ The matrix ensures that island regions close to the mainland (often connected by bridges and tunnels) have neighbours. We also compiled a binary contiguity matrix that provided similar results.

\section{References}

ANGRIST, J.D. and PISCHKE, J.-S. (2009) Mostly harmless econometrics: An empiricist's companion. Princeton University Press, Princeton, NJ.

BOSCHMA, R.A., FRITSCH, M. (2009) Creative class and regional growth: empirical evidence from seven European countries, Economic Geography, 85, 391-423

BROWN, J.P., LAMBERT, D.M., FLORAX, J.G.M. (2013) The birth, death, and persistence of firms: Creative destruction and the spaatial distribution of U.S. manufacturing establishments, 2000-2006, Economic Geography, 89, 203-226

CARLINO, G.A., MILLS, E.S. (1987) The determinants of county growth, Journal of Regional Science, 27, 39-54

CARRUTHERS, J.I., MULLIGAN, G.F. (2008) A locational analysis of growth and change in American metropolitan areas, Papers in Regional Science, 87, 155-171

CLARK, D.E., MURPHY, C.A. (1996) Countywide employment and population growth: An analysis of the 1980s, Journal of Regional Science, 36, 235-256

DORLING, D. (1995) The visualization of local urban change across Britain, Environment and Planning B: Planning and Design,22, 269-290

ELIASSON, K., LINDGREN, U., WESTERLUND, O. (2003) Geographical labour mobility: migration or commuting?, Regional Studies, 37, 827-837

ESCRIBÁ, J.P., MURGUI, M.J. (2013) New estimates of capital stock for European regions (1995-2007), Revista de Economia Aplicada, 21, 1-25 
GRILICHES, Z. (1967) Distributed lags: A survey, Econometrica, 35, 16-49

HOOGSTRA, G.J., FLORAX, R.J.G.M., VAN DIJK, J. (2005) Do 'jobs follow people' or 'people follow jobs'? A meta-analysis of Carlino-Mills studies. Paper for the 45th ERSA Congress, Amsterdam.

HUGGINS, R., CLIFTON, N. (2011) Competitiveness, creativity and placebased developmen, Environment and Planning A, 43, 1341-1362

ISAKSEN, A. (2005) Den kreative klassen og regional næringsutvikling i Norge. NIFU-STEP Arbeidsnotat, 22/2005.

LAMBERT, D.M., XU, W., FLORAX, J.G.M. (2014) Partial adjustment analysis of income and jobs, and the growth regimes in the Appalachian region with smooth transition spatial process models, International Regional Science Review, 37, 328-364

MCCLAIN, K.T., WOOLDRIDGE, J.M. (1995) A simple test for the consistency of dynamic linear regression in rational distributed lag models. Economic Letters, 48, 235-240

MOILANEN, M. (2010) Matching and settlement patterns: the case of Norway, Papers in Regional Science, 89, 607-623 